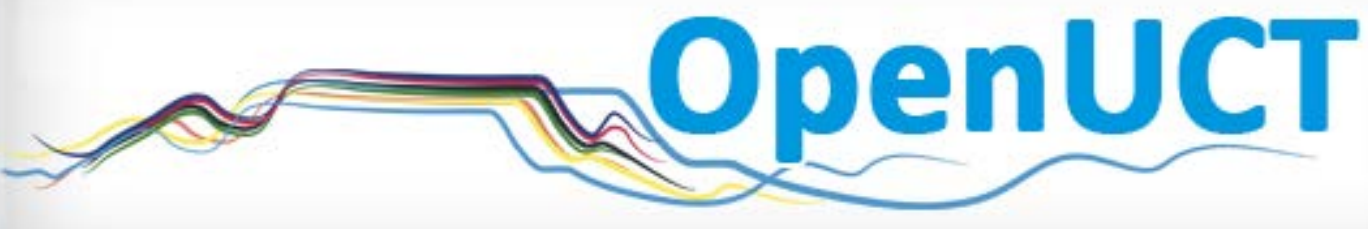

This is the post-print of Archer, A. 2014. Designing multimodal classrooms for social justice. Classroom Discourse. 5(1): 106-116. DOI: 10.1080/19463014.2013.859842.

It is made available according to the terms of agreement between the author and the journal, and in accordance with UCT's open access policy available:

http://www.openuct.uct.ac.za/sites/default/files/UCTOpenAccessPolicy.pdf, for the purposes of research, teaching and private study. 


\title{
Designing multimodal classrooms for social justice
}

Arlene Archer

Writing Centre, Centre for Higher Education Development, University of Cape Town

\begin{abstract}
This paper explores the ways in which multimodal classroom discourse could inform a social justice agenda through broadening the base for representation in the classroom. It identifies some of the challenges and opportunities of designing multimodal classrooms in diverse and developing contexts, where there are vast differentials in terms of access to resources. It focuses on the ways in which multimodal classrooms could recognize a range of student resources, whilst at the same time enabling access to dominant forms. This includes access to the discourses and knowledges of official curricula, and formal methods of assessment, as well as the creation of dispositions towards meaning-making outside of the classroom. Formal education often closes down access to a range of semiotic resources and multimodal classrooms can potentially recover 'recognition' of these. This paper explores ways of designing multimodal classrooms for social justice in order to surface the range of students' resources which are often not noticed or valued in formal educational settings. It proposes the following: the questioning of boundaries between domains, harnessing students’ representational resources, developing metalanguages for reflection, and creating less regulated classroom spaces.
\end{abstract}

\section{Key words}

Multimodality, access, recognition, social justice 


\section{Introduction}

This paper explores ways of designing multimodal classrooms for social justice, looking at examples from some South African classrooms. It showcases interventions in a range of disciplinary domains, including Pharmacology, Communication Studies, Civil Engineering, and English. The challenge is to facilitate recognition of students' diverse resources, whilst at the same time enabling access to the content and discourses of official curricula and formal methods of assessment. Multimodal classrooms go beyond written and spoken language to overtly encourage classroom tasks that require multiple forms of representation, such as writing, image, speech, gesture and music. This paper argues that broader conceptions of semiotic resources and ways of communicating could allow for reconceptualising which textual practices count and for whom, thus highlighting relations of power, inequality and social boundaries. In South Africa, teachers and theorists drawing on multimodal approaches have tended to interrogate power differentials and social justice (Archer 2006; Harrop-Allin 2011; Newfield 2011; Stein 2008; Stein and Newfield 2006; Thesen 2001, 2007). Resources like local languages and indigenous knowledge practices were undervalued under the previous political regime, and many teachers and researchers have attempted to recognize a range of students' resources which are often not valued in formal classroom settings, including cultural forms and knowledges. In educational contexts in South Africa there is still differential access to education and to resources such as textbooks, computers, teachers. The medium of instruction remains predominantly English. However, students have multiple language systems to draw on, and there is often a degree of fluidity and movement between languages and language varieties. In order to recognize the resources that marginalized South Africans have developed, it is necessary to focus on student agency in textual design.

\section{Recognition, agency and choice}

An approach that takes into account the full range of semiotic resources has the potential to make classrooms more democratic and inclusive. Such an approach could enable marginalized students' histories, identities, languages and discourses to emerge through “broadening the base for representation” (Stein and Newfield 2006: 9). ‘Recognition’ of resources is an important feature of designing multimodal classrooms for social justice. 'Recognition' is about noticing resources in terms of some existing framework and integrating these in a range of contexts. The use of modes in classrooms is always "the effect of the work of culture, history and power in shaping materials into resources for meaning- 
making” (Stein 2008, 122). So, recognition of resources also entails recognition of how power is operating in varying social practices. By resources, I mean both students' resources, as well as semiotic resources, such as colour. People choose how to represent meaning from a range of possible options which are crucially shaped within a particular context. This may mean drawing on resources that were previously devalued and marginalized to the extent that they were deemed inappropriate in an educational setting. The meaning-maker can, however, choose to re-evaluate these resources, to assess their value for the immediate contexts and to select according to criteria, context and design. Recognition thus also entails self-reflexivity and the ability to understand this notion of semiotic choice.

As an example of how choice operates, I will look at a student's text that combines writing and information graphics. The example in figure 1 below is taken from a $\mathrm{PhD}$ thesis in medical virology in the Health Sciences. The aim of the PhD is to investigate the therapeutic role of two vaccinations (the 'humanized recombinant vaccinia virus complement control protein' (hrVCP) and the 'vaccinia infected mammalian cell derived authentic VCP') in Ischemia/Reperfusion ( $/ / \mathrm{R})$ injury of the kidney in rats. The choice of information graphic and how to configure it is important in order to construct an argument in this particular context. In this graphic, the argument is that the injured and treated (VCP/hrVCP) group of rats recovered better than the injured and untreated (PBS) group. The confidence interval information, using the standard error of the mean (SEM) in the chart, allows for the comparison of the three groups. The three groups include the treated rats, untreated rats and the sham or control group which comprises rats which have not been injured or treated. The label on the horizontal axis is 'groups'. The subjects, namely rats, are removed in this label, resulting in abstraction of the chart from a particular context, which is characteristic of scientific discourse.

The student has chosen a bar chart with confidence intervals to represent his data. He could have chosen a table format, which would have impacted on the type of information it is possible to display. For instance, displaying the sample size would have been more likely in a table, whereas its absence in the bar chart is not so obvious. The chart comprises blue bars on a grey background which is the default design in Excel. There are a host of other design choices that the student could have made, such as using different colours, different spacing between bars, a more finely calibrated vertical axis for ease of comparison. However, the 
bulky size and shape of the bar does give more visual weight to the argument than a single point would and the wide spacing between the bars creates a clear distinction between the different groups.

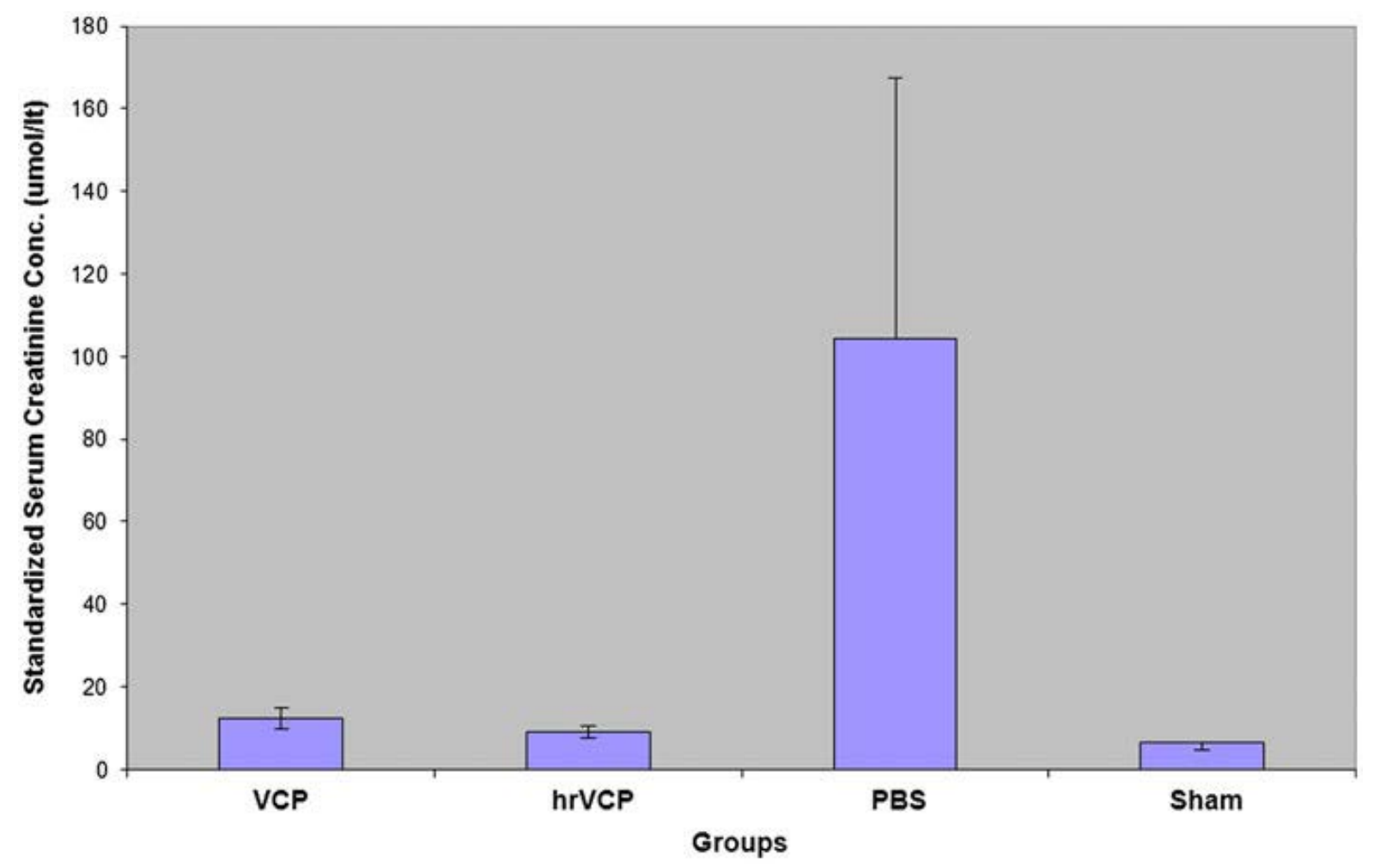

Figure 1. Extract from a PhD thesis in Medical Virology in the Health Sciences

As a counterpoint to these 'safe' representational choices, it is worth thinking about information graphics which are composed somewhat differently. By calling his book Information is Beautiful, McCandless (2009) draws overt attention to the 'aesthetic' potential of information graphics. There are design choices to be made here in terms of size, shape, colour, and composition in order to represent an argument to a particular audience in the most apt way.

The representation in figure 2 is also a comparison. McCandless compares tons of carbon emitted annually and uses iconic shapes for comparison rather than rectangular ones.

However, these shapes have not been scaled to size, indicating a rhetorical decision rather than a statistical one. Because the representation is organized in spatial rather than linear terms, one could tell many stories from the information, not necessarily in any particular order. However, by placing the tree in the upper left corner, the relationship of it to the other 


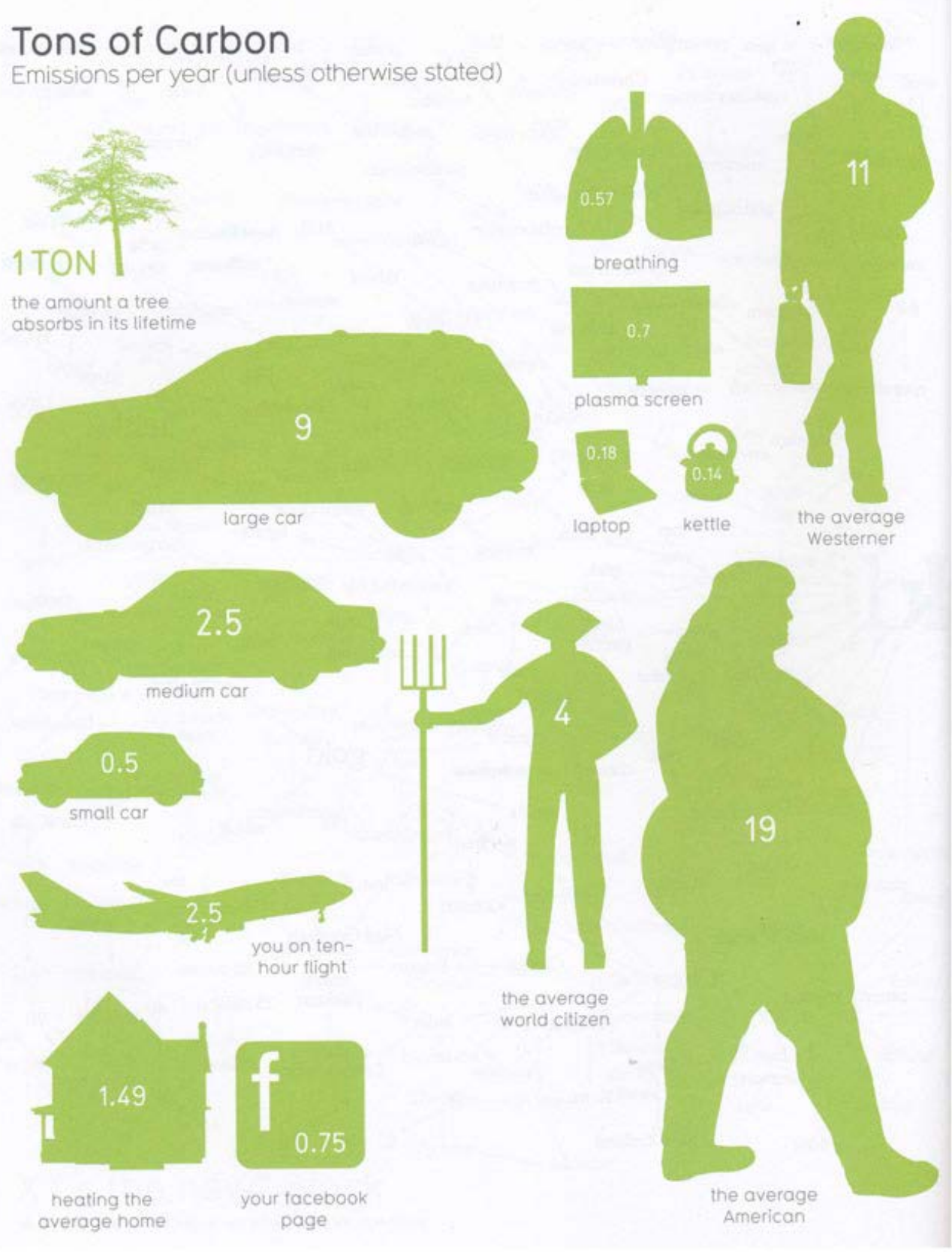

Figure 2. Tonnes of carbon emitted annually (McCandless 2009, 26) Reproduced with permission from David McCandless (c) 2009.

categories or objects is encouraged. The choice of items to compare (individual house, car, air travel and large human) reflects the argument which the author wishes to make, namely that individual and excessive consumption cause carbon emissions and have a harmful effect on the environment. Whilst recognizing that this information graphic is embedded in particular socio-political discourses and realized in journalistic genres, it is useful in 
demonstrating a different kind of authorial agency and power-differential than the studentproduced graphic. The representational choices made here may not be appropriate in an academic environment, whereas they may function well in the social domain where form and readability need not be as closely aligned. How and why people choose to represent from a range of options points to the notion of design; the process of giving shape to the interests of the sign-maker for an assumed audience using the available semiotic resources (Bezemer and Kress 2008: 174). These choices are always expressions of ideology and power - what choices were made and for what purposes?

Multimodal classroom discourse as sign production, reception and transformation, can thus be understood as student's active engagement with the semiotic resources available to them at a particular moment in a specific socio-cultural context (Kress 1997). Bearing this in mind, I will now focus on exploring some ways of designing multimodal classrooms for social justice, looking at examples from different educational sites in South Africa. The examples refer to a number of contexts in Higher Education and a High School poetry project, yet the principles could be applied to classrooms in other contexts, spanning different age ranges.

\section{Burring boundaries between domains.}

One way of creating more semiotically open classrooms is to set tasks that work across disciplines and defined domains of knowledge, as well as across a range of modes, media and genres. Bernstein (1996) points out that power is maintained and relayed through the creation of boundaries between practices, and it is often in 'mixed' forms where power is played out. Questioning or reinterpreting some standard generic conventions can signal an encounter of diverse knowledges and differently organized social worlds.

An interesting example of this kind of blurring of boundaries between disciplinary, professional, private and public domains is a project in a fourth year pharmacology course (Weiss, forthcoming). In the project, students produce a pamphlet or other Health Promotion materials, get feedback from a patient and write a reflective critique on the process, including their design, content and ethical considerations. The aim is to enable medical students to learn how to adapt and personalize clinical information for individual patients from diverse educational, language, economic and socio-cultural backgrounds. Producing health promotion materials requires students to draw on resources from a range of domains, 
including clinical environments which provide access to academic knowledge about disease as well as professional environments that construct 'ways of being a doctor'. Weiss argues that a social semiotic analysis of the student-produced texts is useful to identify underlying assumptions (in this case, assumptions about sexual behaviour). Recognizing these assumptions is important in order to feed back into the design of the medical curriculum. She looks at how the student pamphlets on contraception construct views on reproductive responsibility, male-female relationships, doctor-patient relationships, disease, morality. This is done by pushing the boundaries of the pamphlet genre which is realized through images, layout, writing, as well as 'interactivity’. For example, one pamphlet requires the reader to 'unbuckle the belt' in order to open the pamphlet, which has a tag on the front, 'Ready for sex?' These views on contraception often co-exist alongside contemporary discourses of the market place. The students thus draw on semiotic and discursive resources in professional, private and public domains for meaning-making.

In the above project, recognition is linked to development and 'transformed practice' (New London Group 2000). Student resources are validated and are used to provide access to the professional discourses valued in academic educational contexts as well as the medical profession. Weiss argues that the process of 'conscious design' within a framework of social semiotics represents a way of developing patient-centered communication practices amongst medical students, as well as preparing the students for the challenges of a multicultural and socially diverse working environment. We can see that this multimodal classroom stresses the making and production of meaning, rather than the acquisition of received knowledge or critique of received knowledge. Fundamental to the notion of multimodality employed in a social justice agenda is the concept of transformation, that meaning-making does not so much involve use of a system, as the transformation of available resources.

\section{Harnessing students’ resources}

In designing multimodal classrooms for access and social justice, the discourse and knowledge of the discipline should be made available, whilst students' resources are simultaneously utilized and validated. Projects are not simply springboards for students, but are a serious interrogation and utilization of students' representational resources. This enables a shift in power relations in the classroom from top-down imposition to negotiation and discussion. Also, discursive and generic conventions are brought into focus in order to show 
what kinds of social situations produce them, and what the meanings of these social situations are. Only resources which are visible can become available as elements in conscious design processes. In this way, different ways of thinking and practice in representation become available as resources for students and there is an expansion of the repertoire of resources in order to create semiotically open classrooms. This includes multilingualism, indigenous and local cultural and semiotic practices.

Some of my own work explores ways of harnessing students' resources in different disciplinary sites in Higher Education. I have looked at ways of establishing a dialogue between less regulated spaces in the curriculum and the texts that emerge from them, and the more regulated genres of the curriculum so that students' representational resources can be utilized in innovative ways. An example of this is a Symbolic Object project in a first year Communication Course in an engineering foundation programme. In the project, students identify everyday objects that have symbolic meanings and examine these in a range of physical, cultural and communicational contexts. The aim of this pedagogical intervention was to use objects and symbolism in order to engage with questions of diversity and identity. Objects are seen as a way of eliciting student narratives, exploring dynamic and conflicting cultural practices, highlighting notions of change and focusing on recontextualization of meaning in new contexts (Archer 2007).

The objects the students identified were often aspirational like a microwave in a community without electricity, and the steps at Jameson Hall, a popular place to hang out on our campus, but also the place where you graduate. Various religious objects were identified, and a number of animals, including a goat and the rituals around slaughtering. Many of these objects indexed change in one way or another, and highlighted shifts and contradictions in certain cultural practices. For instance, beer in South African society has different meanings for different contexts. According to the students, it highlights issues of generation, class, cultural groupings, economics and crime. In terms of generational aspects, traditional beer is not drunk by young people because it symbolises 'manhood'. On the other hand, 'modern' beer is drunk more by young people. The students highlighted that beer drinking culture differs across groups in our society:

Whites drink beer to celebrate something ... Black people especially the Zulus, use beer (traditional beer) when they have feasts ... to communicate with their ancestors. 
This example shows how a project like the Symbolic Object intervention could draw on students' socio-cultural resources in order to raise questions around diversity and identity in the classroom. The students produced a short research project around these issues, drawing on multimodal semiotic resources to do so.

By advocating a curriculum that sets up a dialogue with students' resources in order to 'harnesses' them, I do not mean simply using these resources, but encouraging students to critically interrogate them. I have examined the ways in which the resources used in less regulated curriculum spaces can be utilized in more formal, high-stakes assessment curriculum tasks, and looked at how underlying systems of classification transfer across contexts, for instance from the 'mythical' to the 'scientific' where part-whole structures and transformative processes operate (See Archer 2010 for an argument that mystical knowledge may have the same function as science in particular communities, as both are about constructing relations between elements in the natural world). The notions of convention and change that a pedagogical intervention such as the Symbolic Object project raises are important to explore. 'Change' need not necessarily mean 'loss', but needs to be conceived of as additive. We need to be aware of and respect cultural norms and values, but at the same time, begin to look at these critically and with constructive lenses.

\section{Developing metalanguages of reflection}

In order to development an environment of recognition, it is useful to be able to theorize and understand resources using a metalanguage. A metalanguage can "identify and explain difference between texts, and relate these to the contexts of culture and situation in which they seem to work” (NLG 2000, 24). Metalanguages are thus important in achieving conscious awareness of the nature of the resources being used and for this reason, they can feed into assessment criteria. However, complex metalanguages can be daunting for many students and could hinder rather than enhance the learning experience. Thesen (2001) suggests that rather than propose an entirely new vocabulary and new ways of understanding the world, a metalanguage should serve as "an index of discourse - ways of verbalising what you know in relation to other ways of knowing” (143).

In a study on technical drawing in a civil engineering diploma, Simpson (forthcoming) stages a two part argument involving metalanguage and access. He argues that the semiotic domain 
of Civil Engineering drawing is particularly stable, and thus governed by sometimes invisible rules and conventions. Some students may be less familiar with these 'taken-for-granted' ways of drawing than others, which could disadvantage them in the classroom. Firstly, he identifies and makes explicit key resources which are used in drawing, including line thickness, line continuity, the type of lead used, conventions governing the representation of particular materials such as screed or concrete or stone. Secondly, he develops a way of talking about drawing in order to highlight the often unconscious norms and conventions that students become socialized into. This includes aspects like modality or the credibility of the drawing which he defines in terms of criterial partiality, composition, framing and abstraction. It also includes conventional practices such as labelling, dimensioning, framing and accuracy. Here, the metalanguage developed provides a way of making explicit the norms and conventions operating in the tightly regulated domain of engineering drawing. This may be useful in enabling student access into this domain.

I have argued elsewhere (Archer 2012) that we need to expand the notion of a 'metalanguage' to that of 'metaforms'. By 'metaform', I refer to a means of description and analysis that can work across modes. Although it is more common to use the written mode to reflect on the visual, it is possible for an image to reflect on another image or on writing (as in satirical cartoons and various kinds of culture jamming). Using these kinds of 'metaforms' for reflection in the classroom could ignite critical thought and dialogue. Teaching students how to do textual analysis can draw attention to social boundaries and inequality. Textual analysis enables access to understanding and debunking of dominant discourses, rather than seeing these as fixed and natural. Texts reflect and recycle different discourses. Some of these discourses may complement each other, and others may compete with each other or represent conflicting interests or ideologies. This is Bakhtin's (1981) notion of dialogism, the recognition of the polyvocality of any sign. In culture jamming, for example, the tension between these competing discourses is foregrounded in order to pass critical commentary on a social issue. Multimodal classrooms can open up spaces for interrogating which texts are valued and why, thus highlighting relations of power.

\section{Creating less regulated curriculum spaces}

In designing multimodal classrooms for social justice, it is important to include less regulated spaces in order to increase students' choices and allow scope for reflection. These include 
physical as well as virtual spaces, such as online chats. In these spaces, students can experiment with multimodal representation, draw on a range of discourses and employ humour or irony. They can draw on primary discourses as well as secondary discourses to create metalanguages to make sense of the curriculum.

By way of illustrating the power of these less regulated spaces, I will briefly look at a project which drew on African popular culture to revitalize the poetry curriculum at a High School in Soweto (Newfield and Maugedzo 2006). Newfield's work on language and literacy and literature education in South Africa has combined multimodal classroom and textual practices with social justice education. The mainstream approach to the teaching and learning of poetry in South Africa is 'analysis'. In this project, Newfield and Maugedzo shifted the curriculum focus from analysis to composition, which enabled the students to produce poetry in different ways - as a spoken form, as performance, and even as embroidered cloth. Changing the audience, meant the students could write poetry to friends, and, finally, even produce an alternative poetry anthology to the school anthology. It was the 'freeing up' of poetry in a low stakes informal environment using multimodal means that made this particular pedagogical intervention such a success. Here hegemonic language and pedagogic practices were challenged, whilst simultaneously providing access to dominant language practices. This example illustrates how less regulated curriculum spaces can enable students to draw on and experiment with a range of genres and modes. This can open up opportunities for exchange of cultural and personal knowledge, and create opportunities for students who may have been marginalized in the classroom to find a legitimate voice.

\section{Challenges in designing multimodal classrooms}

Although there are many instances of multimodal pedagogical interventions and research projects that have resulted in social change, I would also like to sound a cautionary note. For instance, when some student teachers at a South African university were asked how they would employ the ideas around multimodal pedagogies in the classroom, they evidenced confusion around underlying notions of culture. For instance, the following 'learning outcomes' were listed by one student teacher for an activity around symbolic objects in the classroom:

- The learners will be able to use materials and objects to show how they have grown/changed. 
- Learners will be able to identify different clothes for different cultures.

These are very different orders of outcome revealing conflicting views on culture. The first outcome is about culture as change, and the second about culture as stasis. The notion of culture as static and not about change and flux was common amongst this group of student teachers and is reflected in the following statement:

This classroom activity can be introduced by asking learners to tell us more about their cultures. They can also wear different cultural clothes on a certain day, to learn more about cultural differences. So that they can appreciate the diversity of culture. They can also bring different food used in their cultures.

The tragedy of this proposed classroom activity is that it lapses into a crude multiculturalism where clothes and food signify 'culture' which is seen as having distinct boundaries. Even if student-teachers ostensibly talked of culture as a 'resource' (Thornton 1988), rather than as a 'thing', their thinking often lapsed into basic forms of compartmentalization, essentialism and stereotyping, which has proved to be so dangerous in our past history. I think what this exercise revealed to me is how carefully this subject matter needs to be handled in the classroom, and also, how deeply entrenched stereotypical thinking is in South African society which continues to be polarized.

It is clear that simply including a range of modes and text types in the curriculum, does not necessarily enable student access. This kind of 'mode determinism' could lead to instrumentalism and the kind of crude multiculturalism demonstrated above. It is worth noting that the classroom is always multimodal. What I am proposing here is a broader social semiotic approach that sees modes in a particular way. I am not proposing that the use of different modes necessarily generates the ideological and epistemological shifts in the classroom. It is not the broadening out of modes that has these effects, but rather the deeper ideological issues that underpin their uses in these ways. Other challenges could include harnessing the energy and emotions that are sometimes unleashed in these kinds of less regulated spaces. For instance, in Stein’s (2008) Olifantsvlei Fresh Stories project the children gave horrifying accounts of violent incidents from the impoverished, politicized and violent environments in which they lived. Containing and framing those experiences is vital for students to process them both individually and collectively. This is important in terms of recognizing and harnessing students' resources in order to ultimately produce critical and humane citizens. 


\section{Final comments}

This paper has reflected on ways of designing multimodal classrooms in relation to power and social justice. I have argued for the importance of this as there is still differential access to economic, educational and cultural resources in our society and institutional discursive practices in education can serve to exclude particular groups. My main argument is that we need to see recognition in relation to access in the broadest sense and not just access to existing norms. If we understand recognition as simply noticing or theorizing resources, this runs the risk of institutionalizing situated practice. While it is educationally sound to validate local practices and resources, access to dominant practices has to be provided at the same time (Janks 2000). Thinking of classroom discourse as socio-historically situated, draws attention to the contested nature of dominant conventions. Of particular interest in terms of social justice is the extent to which we can create unregulated spaces in order to enable a range of student resources to emerge, as well as the ways in which we can enable access to dominant forms in multimodal ways. Equally important, is the development and use of accessible metalanguages of "reflective generalization that describe the form, content and function of the discourses of practice” (New London Group 2000: 24) to enable students to discuss and critique texts across contexts. The interventions described in this paper acknowledge "learners as agentive, resourceful and creative meaning-makers” (Stein and Newfield 2006: 8). They place a strong emphasis on student 'interest' and agency. Classrooms which both draw on and validate students' practices, resources and discourses are invaluable, as they enable students to interrogate their past situations and aspirations, to reflect on dominant norms and practices, whilst providing access to these at the same time.

\section{References}

Archer, A. 2012. Writing as design. Enabling access to academic discourse in a multimodal environment. South African Journal of Higher Education 26, 3: 411 - 421.

Archer, A. 2010. Shamanism and Science: Reciprocal curriculum as transformative.

Education as Change. 14, 1. 61 - 75. 
Archer, A. 2007. 'No goats in the mother city': Using Symbolic Objects to help students talk about diversity and change. English in Education 41, 1: 7 - 20.

Archer, A. 2006. A multimodal approach to academic 'literacies': problematizing the visual/verbal divide. Language and Education 20, 6: 449 - 462.

Bakhtin, M. 1981. Discourse in the novel. (M. Holquist ed. and trans). The Dialogic Imagination. Four Essays by M. Bakhtin. Austin: University of Texas Press.

Bernstein, B. 1996. Pedagogy, Symbolic Control and Identity. Theory, Research, Critique. London: Taylor and Francis.

Bezemer, J. and Kress, G. 2008. Writing in multimodal texts. A social semiotic account of designs for learning. Written Communication 25, 2: 166 - 195.

Harrop-Allin, S. 2011. Playing with Barbie: exploring South African township children's games as resources for pedagogy. In L. Green. (ed.) Learning, Teaching and Musical Identity: Voices across Cultures. Bloomington: University of Indiana Press. 156 - 169.

Janks, H. 2000. Domination, access, diversity and design: a synthesis for Critical Literacy education. Educational Review 52, 2: 175 - 186.

McCandless, D. 2009. Information is Beautiful. London: Collins.

Newfield, D. 2011. Multimodality, social justice and becoming a really South African democracy: case studies from language classrooms. In Social Justice Language Teacher Education, ed. M. Hawkins. 23 - 48. Bristol, UK: Multilingual Matters. 23 - 48.

Newfield, D. and Maungedzo, R. 2006. Moblising and Modalising Poetry in a Soweto Classroom. English Studies in Africa 49, 1: 71-93. 
New London Group. 2000. A Pedagogy of Multiliteracies: Designing Social Futures. In Multiliteracies. Literacy Learning and the Design of Social Futures, eds B. Cope and M. Kalantzis. London and New York: Routledge.

Simpson, Z. (forthcoming) Resources, representation and regulation in Civil Engineering Drawing: An autoethnographic perspective. In Multimodal approaches to research and pedagogy: Recognition, resources and access, eds. A. Archer and D. Newfield. Routledge. Stein, P. 2008. Multimodal pedagogies in diverse classrooms, representation, right and resources. London, New York: Routledge.

Stein, P. and Newfield, D. 2006. Multiliteracies and Multimodality in English in Education in Africa: Mapping the Terrain. English Studies in Africa 49. 1: 1 - 22.

Thesen, L. 2001. Modes, Literacies and Power: A University Case Study. In Language and Education 14, 2 and 3. $132-145$.

Thesen, L. 2007. Breaking the frame: lectures, ritual and academic literacies. Journal of Applied Linguistics 4, 1: 33 - 53.

Thornton, R. 1988. Culture: A contemporary definition. In The Uses and Abuses of Political Concepts, eds. E. Boonzaier and J. Sharp. Cape Town and Johannesburg: David Phillip.

Weiss, R. (forthcoming). Multimodality and Medicine. In Multimodal approaches to research and pedagogy: Recognition, resources and access, eds. A. Archer and D. Newfield. Routledge. 